\title{
EVALUASI TINGKAT ADOPSI TERHADAP INOVASI PEMBUATAN KONSENTRAT PADA KELOMPOK PETERNAK SAPI POTONG RAKYAT KABUPATEN MALANG
}

\author{
Evaluation the Adoption Rate of Concentrate Processing Innovation in Group \\ of Smallholders Beef Cattle Farmers in Malang Regency
}

\author{
Afifah Juniyar Luthfi ${ }^{1)}$ dan Siti Azizah ${ }^{2)}$ \\ 1) Mahasiswa Minat Sosial Ekonomi Peternakan, Fakultas Peternakan, Universitas Brawijaya Jalan Veteran, \\ Ketawanggede, Kec. Lowokwaru, Kota Malang, Jawa Timur 65145 \\ 2) Dosen Minat Sosial Ekonomi Peternakan, Fakultas Peternakan, Universitas Brawijaya Jalan \\ Veteran, Ketawanggede, Kec. Lowokwaru, Kota Malang, Jawa Timur 65145 \\ Email: siti.azizah@ub.ac.id
}

\begin{abstract}
ABSTRAK
Penelitian berlangsung pada tanggal 25 November 2018 sampai 15 Februari 2019 di Desa Senggreng, Kecamatan Sumberpucung Kabupaten Malang. Tujuan penelitian ini adalah untuk mengetahui hubungan antara peran penyuluhan dengan adopsi inovasi. Responden dari penelitian ini berjumlah 32 anggota Kelompok Ternak Rojo Koyo. Variabel yang di teliti pada penelitian ini antara lain: 1) peran penyuluhan dengan indikator (edukasi, diseminasi, fasilitasi, consultasi, supervisi, monitoring dan evaluasi) 2) adopsi inovasi dengan indikator (perubahan pengetahuan (cognitive), perubahan sikap (affective) dan perubahan keterampilan (psychomotor). Analisis data menggunakan SPSS 23.0 dilanjutkan dengan metode deskriptif kuantitatif dan cross tabulation. Hasil itu menunjukan indikator memberikan pengaruh yang tinggi dalam peran penyuluhan: 1) variabel edukasi: pemilihan bahan baku (skor 3,84); 2) variabel diseminasi: peningkatan bobot badan (skor 3,88); 3) variabel fasilitasi: pembukuan kegiatan Kelompok Rojo Koyo (skor 4,06); 4) variabel konsultasi: penyelesaian masalah terutama saat penerapan adopsi inovasi (harga bahan baku mahal) (skor 4,28); 5) variabel supervisi: pengembangan teknik pertanian (skor 4,03); 6) variabel monitoring dan evaluasi: kualitas konsentrat (skor 4,19). Variabel adopsi inovasi menunjukkan bahwa perubahan perilaku pengetahuan (cognitive) (skor 4,00). Variabel adopsi inovasi menunjukkan bahwa perubahan perilaku sikap (affective) (skor 3,94). Variabel adopsi inovasi menunjukkan bahwa perubahan perilaku keterampilan (psychomotor) (skor 4,16). Hubungan cenderung positif terdapat pada indikator edukasi terhadap perubahan perilaku pengetahuan, sikap dan keterampilan, sedangkan hubungan cenderung positif dan negatif terdapat pada indikator diseminasi terhadap perubahan perilaku pengetahuan.
\end{abstract}

Kata Kunci : Peran penyuluhan, adopsi inovasi.

How to Cite :

Luthfi, A., \& Azizah, S. (2019). Evaluasi Tingkat Adopsi Terhadap Inovasi Pembuatan Konsentrat pada Kelompok Peternak Sapi Potong Rakyat Kabupaten Malang. Jurnal Nutrisi Ternak Tropis 2 (2) 80-88
*Corresponding author :

Siti Azizah

Email : siti.azizah@ub.ac.id

Fakultas Peternakan, Universitas Brawijaya Jalan

Veteran, Ketawanggede, Kec. Lowokwaru, Kota Malang, Jawa Timur 65145 


\section{ABSTRACT}

The research was conducted on November 25th, 2018 until February 15th, 2019 in Senggreng Village, Sumberpucung sub-district, Malang Regency. The research aims to determine the correlation between the roles of extension to innovation adoption. Responden of the research were 32 members of Rojo Koyo farmer group. Variables observed were: 1) the role of extension (education, dissemination, facilitation, consultation, supervision, monitoring and evaluation) 2) Innovation adoption (cognitive, affective, and psychomotor). Data were analyzed by using SPSS 23.0 continued by descriptive quantitative method and Cross Tabulation. The results showed indicators gave highest affect in role extension: 1) education variable: selection of raw material reserve (Score 3,84); 2) dissemination variable: increase in cattle body weight (Score 3,88); 3) in variable of facilitation: bookkeeping activities of the Rojo Koyo group (Score 4,06); 4) In Consultation variable: the problems solving especially when innovation adoption (expensive raw material price) (Score 4,28); 5) In Supervision variable: farming technique development (Score 4.03); 6) In Monitoring and evaluationvariable: quality of concentrate (Score 4.19). Variables of innovation adoption showed that cognitive change (Score 4.00). Innovation adoption variables showed that affective change (Score 3.94). Variables of innovation adoption showed that psychomotor change (Score 4.16). The correlation tends to be positive of education on changes in cognitive, affective and psychomotor. The correlation tends to be positive and negative of dissemination in cognitive changes.

Keywords: Role of extension, innovation adoption.

\section{PENDAHULUAN}

Negara Indonesia adalah negara agraris dengan sub sektor peternakan yang tersebar dari hulu ke hilir. Sektor peternakan pada wilayah kabupaten Malang sangatlah beragam mulai dari komoditi lebah, ayam, kelinci, domba, kambing, sapi potong, sapi perah dan masih banyak lagi.

Berdasarkan data yang dihimpun Badan Statistik Kabupaten Malang (2018) menjelaskan bahwa pertumbuhan sapi potong tahun 2009 hingga 2016 fluktuatif namun cenderung mengalami kenaikan. Tahun 2009 populasi sapi potong sebanyak 142.344 ekor, mengalami kenaikan pada 2010 menjadi 147.865 ekor pada 2011 populasi ternak mengalami kenaikan yang tertinggi sebanyak 225.895 ekor, pada tahun 2012 mengalami kenaikan sebanyak 240.746 ekor, pada tahun 2013 mengalami peningkatan yang melambat dengan angka populasi terendah sebanyak 189.145 ekor, tahun 2014 sebanyak 199.453 ekor, tahun 2015 sebanyak 212.821 ekor, dan 2016 jumlah populasi sapi potong sebanyak 223.717 ekor. Berdasarkan data tersebut menunjukkan bahwa sektor peternakan belum berjalan secara maksimal, hal tersebut dikarenakan presepsi masyarakat bahwa berternak sama dengan menabung hewan, sehingga hewan hanya dijual saat keadaan ekonomi terdesak yang berakibat kurang efektifnya produktifitas ternak. Program penyuluhan merupakan langkah pemerintah pada sektor peternakan sebagai penunjang wawasan dan inovasi baru yang dapat diterapkan pada masyarakat sehingga beternak bukan hanya sekedar kegiatan menabung hewan.

Dalam rangka peningkatan produksi peternakan Kabupaten Malang Dinas Peternakan dan Kesehatan Kabupaten Malang memberikan program pembinaan berupa penyuluhan yang di bimbing oleh penyuluh pertanian lapang (PPL). Penyuluhan secara umum merupakan proses pendidikan nonformal yang diberikan pada kelompok ternak sehingga dapat memecahkan masalah dan memberikan inovasi yang inovatif sehingga 
mampu mengikuti perkembangan zaman dan hasil produksi yang dihasilkan maksimal.

Proses penyuluhan berkaitan pada proses adopsi inovasi peternak untuk mengambil keputusan atas ide yang diberikan oleh penyuluh. Inovasi berasal dari luar sistem sosial namun dapat digali dari sumber daya dalam suatu sistem sosial. Menurut Soekartawi (1988) Proses adopsi yang dilakukan melalui dua tahapan yang terdiri dari pengenalan inovasi dan proses penerimaan atau penolakan dari masyarakat, apabila dari proses tersebut menghasilkan keputusan untuk menerima maka akan terjadi proses adopsi.

Peran penyuluhan sebagai fasilitator yang memfasilitasi kepentingan kelompok ternak binaannya sehingga memenuhi tujuan kelompok ternak, indikator peran penyuluhan menurut Mardikanto (2009) dapat dilakukan dengan edukasi yang berarti membuka wawasan anggota kelompok ternak; diseminasi yaitu memperkenalkan teknologi hasil penelitian kepada anggota kelompok peternak; fasilitasi yaitu memfasilitasi anggota kelompok peternak dalam mengakses inovasi; konsultasi berarti penyuluh berperan sebagai narasumber dalam berdisukusi dan pemecahan masalah; supervisi berarti penyuluh melakukan pendampingan; monitoring berarti penyuluh memonitor seluruh kegiatan untuk dievaluasi dan evaluasi yaitu proses penilaian terhadap seluruh rangkaian kegiatan.

Kelompok Ternak Rojo Koyo merupakan salah satu kelompok ternak yang terletak di Desa Senggreng Kecamatan Sumberpucung Kabupaten Malang. Kelompok Ternak Rojo Koyo merupakan kelompok ternak yang memberikan andil dalam peningkatan pendapatan peternak. Kegiatan penyuluhan dalam Kelompok Ternak Rojo Koyo dengan salah satu materi pembuatan konsentrat mandiri dengan tujuan sebagai upaya pengembangan peternakan khususnya komoditas sapi potong pada
Desa Senggreng Kecamatan

Sumberpucung Kabupaten Malang. Variabel adopsi inovasi pembuatan konsentrat mandiri diukur dalam indikator perubahan perilaku pengetahuan (cognitive), sikap (affective), maupun keterampilan (psychomotor). Pengembangan komoditas sapi potong di Desa Senggreng Kecamatan Sumberpucung Kabupaten Malang dibutuhkan peran penyuluhan dalam pengembangan pengetahuan sehingga terjadi peningkatan adopsi.

Penelitian ini perlu dilaksanakan untuk mengetahui hubungan peran penyuluhan terhadap adopsi inovasi, selain itu penelitian ini bertujuan agar penyuluh mampu meningkatkan kinerjanya dalam proses penyuluhan agar adopsi inovasi dapat diterima dan diterapkan oleh Kelompok Ternak dengan mudah. Permasalahan yang diangkat adalah bagaimana interaksi yang dihasilkan dari proses penyuluhan dengan keputusan peternak dalam mengadopsi pembuatan konsentrat mandiri di Kelompok Ternak Rojo Koyo Desa Senggreng, Sumber pucung, Malang sehingga harapannya dapat mengetahui hubungan atau interaksi yang terjadi antara peran penyuluhan terhadap keputusan peternak dalam mengadopsi pembuata konsentrat.

\section{METODOLOGI PENELITIAN}

\section{Metode Pengambilan Sampel}

Pengambilan sampel dilakukan menggunakan metode total sampling. Responden yang diamati adalah keseluruhan anggota Kelompok Ternak Rojo Koyo yang berjumlah 32 orang.

\section{Metode Penelitian}

Penelitian dilakukan dengan metode kuantitatif deskriptif yang diambil dengan cara wawancara dengan diajukan kuesioner yang berisi daftar pertanyaan yang ditujukan kepada anggota Kelompok Ternak Rojo Koyo. Wawancara (interview) dilakukan pada 32 orang anggota kelompok ternak. 


\section{Metode Pengumpulan Data}

Pengambilan data dilakukan dengan cara dokumentasi, wawancara dan observasi. Pengumpulan data dalam penelitian ini meliputi :

\section{Data Primer}

Data primer adalah data yang diperoleh secara langsung dari lokasi penelitian melalui observasi partisipatif dan wawancara terhadap Kelompok Ternak Rojo Koyo dengan mengunakan kuesioner. Menurut Supriyono (2015) observasi partisipatif merupakan pengamatan langsung oleh peneliti dan peneliti ikut terlibat dalam kegiatan tersebut. Penelitian ini peneliti ikut berperan langsung dalam objek yang sedang diteliti, antara lain proses penyuluhan dan kegiatan rutin Kelompok Ternak Rojo Koyo.

\section{Data Sekunder}

Data sekunder adalah data yang diperoleh secara tidak langsung yang umumnya didapat dari literatur atau dokumentasi yang berkaitan dengan penelitian.

\section{Analis Data}

\section{Deskriptif}

Penelitian ini menganalisis bagaimana peran penyuluhan yang meliputi edukasi, diseminasi, fasilitasi, konsultasi, pembinaan, monitoring dan evaluasi terhadap proses adopsi inovasi pada Kelompok Ternak Rojo Koyo di Desa Senggreng Kecamatan Sumberpucung Kabupaten Malang. Analisis deskriptif berupa observasi untuk menganalisis permasalahan yang terjadi dengan melakukan perbandingan, perefleksian, pengkategorian, klarifikasi, penyajian dan melakukan verifikasi data secara keseluruhan untuk menemukan keseragaman dan sifat umum objek yang diteliti (Mubarak, 2010). Penelitian secara deskriptif memiliki tujuan untuk mendeskripsikan dengan sistematis, faktual dan akurat terhadap kasus tertentu. Analisa deskriptif. Kuantitatif digunakan untuk mengukur peran penyuluhan terhadap tingkat adopsi inovasi kelompok ternak yang menggunakan Skala Likert Summated Rating (LSR) dengan skala 1-5.

\section{Skala Likert Summated Rating (LSR)}

Skala likert digunakan untuk memberikan skor dari jawaban yang diberikan responden. Data kualitatif yang diamati dalam penelitian ini adalah variabel independen dan variabel dependen, sehingga data tersebut diukur menggunakan Skala Likert's Summated Rating (LSR). Skor nilai jawaban untuk peran penyuluhan dapat dilihat pada Tabel 1 dan nilai skor presepsi di tampilkan pada Tabel 2 sebagai berikut.

\section{Uji Validitas}

Uji Validitas merupakan pengukuran data untuk menentukan valid tidaknya kuisioner. Menurut Widi (2011) Pengujian validitas dapat dilakukan dengan program SPSS dengan teknik korelasi antara product moment dengan skor tiap butir kuisioner. Instrumen dikatakan valid apabila t hitung > t tabel (signifikasi. 0,05)dan signifikasi sama dengan atau lebih dari $5 \%(0,05)$ dinilai tidak valid.

\section{Uji Reliabilitas}

Uji Reliabilitas data merupakan uji yang digunakan untuk mengkorelasikan data yang diambil dari kuesioner tersebut stabil dan konsisten dari waktu ke waktu (Supriyono,2015) Kuesioner dikatakan reliabel atau handal jika jawaban seseorang sama atau stabil dari waktu ke waktu. Pengukuran reliabilitas ini dapat menggunakan metode Cronbach's Alpha. Apabila nilai Cronbach Alpha lebih besar dari $\mathrm{t}$ table maka dapat dikatakan bahwa kuisioner tersebut reliabel. Menurut Ghozali (2018) menyatakan bahwa jika nilai Cronbach's Alpha $(\alpha)$ 0,70 atau mendekati 1 maka nilai reabilitas data semakin terpercaya. Hal ini menunjukkan hasil nilai statitik Cronbach's Alpa dapat menentukan tingkat relibilitas dari suatu variabel. 


\section{Analisis Cross Tabulation}

Analisis crosstabulation merupakan analisis yang digunakan untuk mengetahui hubungan peran penyuluhan dengan adopsi inovasi. Analisis crosstabulation adalah analisis dalam bentuk tabel, yang menunjukkan tabulasi silang untuk mengidentifikasi dan mengetahui adanya hubungan antar variabel. Analisis crosstab merupakan tabulasi data dalam matriks dari beberapa variabel yang berbeda. Tabel yang digunakan merupakan tabel hubungan antara variabel dalam baris. Djaswadi, Berto dan Aang (2017) menambahkan bahwa analisis crosstabuation (tabulasi silang) digunakan dalam mengidentifikasi interaksi dari setiap variabel yang dinyatakan dalam baris maupun kolom. Umumnya input data berupa skala nominal atau ordinal sehingga hasil data yang didapat menunjukkan hubungan atau interaksi dari penyilangan sampel pada beberapa variabel. Variabel hubungan peran penyuluhan dengan adosi inovasi dalam penelitian ini dianalisis dengan menggunakan analisis tabulasi silang (cross tabulation) dimana software yang digunakan adalah SPSS (Statistical Product and Service Solutions) 23.0.

Tabel 1. Skor nilai jawaban yang diberikan responden untuk peran penyuluhan dan adopsi inovasi

\begin{tabular}{lc}
\hline Persetujuan Terhadap Pernyataan & Skor Nilai \\
\hline Sangat Berperan (SB) & 5 \\
Berperan (B) & 4 \\
Cukup Berperan (CB) & 3 \\
Kurang Berperan (KB) & 2 \\
Tidak Berperan (TB) & 1 \\
\hline
\end{tabular}

Tabel 2. Kategori persepsi peran penyuluhan dan adopsi inovasi

\begin{tabular}{lc}
\hline \multicolumn{2}{c}{ Skor Persepsi } \\
\hline Kategori & Skor Nilai \\
\hline Sangat Berperan (SB) & $4.20-5.00$ \\
Berperan (B) & $3.40-4.19$ \\
Cukup Berperan (CB) & $2,60-3.39$ \\
Kurang Berperan (KB) & $1.80-2.59$ \\
Sangat Kurang Berperan (SKB) & $1.0-1.79$ \\
\hline
\end{tabular}

\section{HASIL DAN PEMBAHASAN}

\section{Pembinaan}

Pembinaan dapat dilakukan untuk pendekataan awal pada peternak agar dapat menerima atau menolak inovasi yang diberikan. Pembinaan disini dilakukan dengan melakukan penyuluhan, karena menurut Mardikanto (2009) menyatakan bahwa penyuluhan memiliki peranan penting dalam menentukan adopsi inovasi. Skor pembinaan dari penyuluhan ditampilkan pada Tabel 3. Peran pendampingan dengan penyuluhan pada adopsi inovasi pembuatan konsentrat Mandiri Kelompok Ternak Rojo Koyo di Desa Senggreng Kecamatan Sumberpucung
Kabupaten Malang mendapatkan skor rataan 3,29. Variabel yang dinilai dari sub variabel adalah edukasi, diseminasi, fasilitasi, konsultasi, supervisi serta monitoring dan evaluasi.

\section{Hubungan Peran Penyuluhan pada Adopsi Inovasi Pembuatan Konsentrat Mandiri}

Hubungan peran penyuluhan dengan adopsi inovasi pembuatan konsentrat mandiri ditinjau berdasarkan perubahan perilaku pengetahuan (cognitive), perubahan perilaku sikap (affective), perubahan perilaku keterampilan (psychomotor) dianalis menggunakan software SPSS 23.0. 
Tabel 3. Skor Pembinaan dari Penyuluhan

\begin{tabular}{|c|c|c|}
\hline Variabel dan Indikator & Skor & Kategori \\
\hline Edukasi & 3,68 & Berperan \\
\hline Kualitas Bahan Baku & 3,31 & Cukup Berperan \\
\hline Pemilihan Bahan Baku & 3,84 & Berperan \\
\hline Cara Pembuatan Konsentrat & 3,81 & Berperan \\
\hline Kualitas Hasil Akhir Konsentrat & 3,65 & Berperan \\
\hline Pemberian Konsentrat Pada Sapi & 3,84 & Berperan \\
\hline Motivasi Dan Minat & 3,59 & Berperan \\
\hline Diseminasi & 3,77 & Berperan \\
\hline Pemerataan Informasi & 3,66 & Berperan \\
\hline Peningkatan Bobot Badan & 3,88 & Berperan \\
\hline Fasilitasi & 3,94 & Berperan \\
\hline Pemberian fasilitas dari pemerintah & 3,91 & Berperan \\
\hline Pembetukan Kelompok Ternak & 3,91 & Berperan \\
\hline Notulensi & 3,97 & Berperan \\
\hline Pembukuan Kegiatan Kelompok Ternak & 4,06 & Berperan \\
\hline Pembukuan Pengeluaran Dan Pendapatan & 3,84 & Berperan \\
\hline Konsultasi & 4,21 & Sangat Berperan \\
\hline Konsultasi Harga Bahan Baku Mahal & 4,28 & Sangat Berperan \\
\hline Konsultasi Ketersediaan Bahan Baku & 4,16 & Berperan \\
\hline Konsultasi Kurangnya Modal & 4,34 & Sangat Berperan \\
\hline Frekuensi Konsultasi & 4,06 & Berperan \\
\hline Supervisi & 3,86 & Berperan \\
\hline \multicolumn{3}{|l|}{ Pembinaan Penerapan } \\
\hline Pembuatan Konsentrat & 3,69 & Berperan \\
\hline \multicolumn{3}{|l|}{ Mandiri } \\
\hline Pembinaan Kemampuan Usaha Tani & 4,03 & Berperan \\
\hline Monitoring dan Evaluasi & 4,17 & Berperan \\
\hline Perbaikan Mutu Konsentrat Mandiri & 4,19 & Berperan \\
\hline Peningkatan Adopsi Inovasi Selanjutnya & 4,16 & Berperan \\
\hline Peran Penyuluhan & 3,92 & Berperan \\
\hline
\end{tabular}

Sumber : Data Primer diolah (2019)

\section{Hubungan Peran Penyuluhan Terhadap Perubahan Pengetahuan (Cognitive)}

Hubungan peran penyuluhan terhadap perubahan pengetahuan (cognitive) dengan indikator konsultasi harga bahan baku mahal terhadap perubahan perilaku pengetahuan (cognitive) ditampilkan pada Tabel 4. Berdasarkan Tabel 4 hasil analisis crosstab menjelaskan bahwa indikator konsultasi harga bahan baku mahal yaitu peran penyuluhan dalam proses konsultasi pemecahan masalah yang dihadapi peternak, terutama permasalahan yang dihadapi saat adopsi inovasi (harga bahan baku yang mahal) terhadap perubahan perilaku pengetahuan (cognitive) memiliki hubungan yang cenderung positif. Hubungan cenderung positif dilihat dari skor cukup berperan, berperan dan sangat berperan. Artinya semakin banyak anggota kelompok ternak mendapatkan konsultasi pemecahan masalah yang dihadapi peternak, terutama permasalahan yang dihadapi saat adopsi inovasi (harga bahan baku yang mahal) maka berperan dalam perubahan pengetahuan anggota Kelompok Ternak Rojo Koyo. Kegiatan konsultasi pemecahan masalah yang ada dalam Kelompok Ternak Rojo Koyo dilakukan pada saat pertemuan rutin dengan penyuluh atau saat 
diadakannya penyuluhan, untuk masalah bahan baku konsentrat yang mahal biasanya di ganti dengan bahan baku yang mudah dicari oleh anggota kelompok ternak sesuai anjuran yang dianjurkan oleh penyuluh sehingga anggota kelompok ternak memiliki pengetahuan baru untuk memilih bahan konsentrat yang murah dan mudah didapatkan. Menurut Dali, dkk (2017) penyuluhan memberikan dampak positif bagi petani maupun peternak, karena dengan adanya penyuluhan akan ada perubahan dari tingkah laku, pengetahuan, tingkat kreativitas teknis yang lebih baik sehingga peternak maupun petani akan lebih produktif sehingga meningkatkan pendapatan dan memperbaiki pola usaha yang dijalankan.

Tabel 4. Hubungan konsultasi harga bahan baku mahal terhadap perubahan perilaku pengetahuan (cognitive)

\begin{tabular}{lccccc}
\multirow{2}{*}{$\begin{array}{l}\text { Konsultasi Harga Bahan } \\
\text { Baku Mahal }\end{array}$} & \multicolumn{2}{c}{ Perubahan Perilaku Pengetahuan $($ Cognitive $)(\%)$} & \multirow{2}{*}{ Total } \\
\cline { 2 - 5 } & $\begin{array}{c}\text { Kurang } \\
\text { Berperan }\end{array}$ & $\begin{array}{c}\text { Cukup } \\
\text { Berperan }\end{array}$ & Berperan & $\begin{array}{c}\text { Sangat } \\
\text { Berperan }\end{array}$ & \\
\hline Cukup Berperan & $1(3,1)$ & $1(3,1)$ & $2(6,3)$ & $1(3,1)$ & $5(15,6)$ \\
Berperan & 0 & $5(15,6)$ & $4(12,4)$ & $4(12,4)$ & $13(40,6)$ \\
Sangat Berperan & $1(3,1)$ & 0 & $8(25)$ & $5(15,6)$ & $14(43,8)$ \\
Total & $2(6,3)$ & $6(18,8)$ & $14(43,8)$ & $10(31,3)$ & $32(100)$ \\
\hline
\end{tabular}

Sumber : Data primer diolah (2019)

\section{Hubungan Peran Penyuluhan Terhadap Perubahan Perilaku Sikap (Affective)}

Hubungan peran penyuluhan terhadap perubahan perilaku sikap (affective) dengan indikator notulensi terhadap perubahan perilaku perilaku sikap (affective) ditampilkan pada Tabel 5 menunjukkan analisis crosstab pada indikator notulensi peran penyuluh dalam pembukuan notulensi penyuluhan terhadap perubahan perilaku perilaku sikap (affective) menunjukkan hubungan cenderung positif dan cenderung negatif.

Hubungan cenderung negatif dilihat dari nilai jawaban cukup berperan, berperan dan sangat berperan notulensi peran penyuluh dalam pembukuan notulensi penyuluhan namun perubahan sikap menunjukkan Kurang berperan. Hubungan cenderung positif dilihat dari tingginya peran penyuluhan berperan terhadap perubahan sikap (affective). Menurut penelitian yang diteliti oleh Narso, dkk (2012) menyatakan peran penyuluhan berhubungan dengan memberikan fasilitas terhadap hal yang berhubungan dengan usaha yang akan dijalankan misalnya dari memberikan fasilitas dalam pembentukan kelompok, melakukan pembukuan dari usaha tani, menentukan modal dan melakukan peminjaman modal untuk usaha yang dijalankan.

Tabel 5. Hubungan notulensi terhadap perilaku perilaku sikap (affective).

\begin{tabular}{lccccc}
\hline & \multicolumn{2}{c}{ Perubahan Perilaku Perilaku Sikap (Affective) $(\%)$} & \\
\cline { 2 - 5 } Notulensi & Kurang & Cukup & & & \\
& Berperan & Berperan & Berperan & Sangat Berperan & Total \\
\hline Cukup Berperan & $2(6,3)$ & $\mathbf{3 ( 9 , 4 )}$ & $1(3,1)$ & $\mathbf{3 ( 9 , 4 )}$ & $9(28,1)$ \\
Berperan & $1(3,1)$ & $3(9,4)$ & $3(9,4)$ & $\mathbf{8}(\mathbf{2 5})$ & $15(46,9)$ \\
Sangat Berperan & $1(3,1)$ & 0 & $\mathbf{6}(\mathbf{1 8 , 8})$ & $1(3,1)$ & $8(25)$ \\
Total & $4(12,5)$ & $6(18,8)$ & $10(31,3)$ & $12(37,5)$ & $32(100)$ \\
\hline
\end{tabular}

Sumber : Data primer diolah (2019) 
Hubungan Peran Penyuluhan Terhadap Perubahan Perilaku Keterampilan (Psychomotor)

Hubungan peran penyuluhan terhadap perubahan perilaku keterampilan (psychomotor) dengan indikator pemilihan bahan baku terhadap perubahan perilaku keterampilan (psychomotor) ditampilkan pada Tabel 6. Berdasarkan Tabel 6 menunjukkan bahwa indikator pemilihan bahan baku yaitu perubahan perilaku keterampilan (psychomotor) karena adanya penyampaian materi pengetahuan tentang pemilihan bahan baku cadangan apabila bahan baku utama tidak tersedia, menunjukkan hubungan yang cenderung positif.

Hubungan cenderung positif dilihat dari skor jawaban berperan dan sangat berperan. Artinya Tingginya penyampaian materi pengetahuan tentang pemilihan bahan baku cadangan berperan terhadap perubahan perilaku keterampilan (psychomotor).

Tabel 6. Hubungan pemilihan bahan baku terhadap perilaku perilaku keterampilan (psychomotor).

\begin{tabular}{|c|c|c|c|c|}
\hline \multirow{3}{*}{ Pemilihan Bahan Baku } & \multicolumn{3}{|c|}{ Perubahan Perilaku Keterampilan (Psychomotor) (\%) } & \multirow{3}{*}{ Total } \\
\hline & Cukup & & Sangat & \\
\hline & Berperan & Berperan & Berperan & \\
\hline Kurang Berperan & 0 & $1(3,1)$ & 0 & $1(3,1)$ \\
\hline Cukup Berperan & $1(3,1)$ & $5(15,6)$ & $2(6,3)$ & $8(25)$ \\
\hline Berperan Sangat & $6(18,8)$ & $5(15,6)$ & $7(21,9)$ & $18(56,3)$ \\
\hline Berperan & 0 & $2(6,3)$ & $\mathbf{3}(\mathbf{9}, \mathbf{3})$ & $5(15,6)$ \\
\hline Total & $7(21,9)$ & $13(40)$ & $12(37,5)$ & $32(100)$ \\
\hline
\end{tabular}

Sumber : Data primer diolah (2019)

Kelompok Ternak Rojo Koyo dalam hal pembuatan konsentrat mandiri sudah mampu memilih bahan baku cadangan apabila bahan baku utama langka atau terlalu mahal dipasaran, namun berdasarkan keterangan yang sudah dihimpun oleh peneliti peternak tersebut awalnya berkonsultasi pada penyuluh apabila bahan utama tidak ditemukan atau terlalu mahal, hingga pada saat ini peternak sudah mampu sendiri menggunakan keterampilan mereka untuk memilih sendiri bahan konsentrat cadangan yang akan digunakan dalam pembuatan konsentrat mandiri. Aminah (2007) menyatakan bahwa penyuluhan merupakan proses dari perubahan yang dihasilkan dari proses pendidikan non formal dalam masyarakat, sedangkan dari sudut pandang keilmuan penyuluhan merupakan organisasi yang tersusun yang bertujuan meningkatkan taraf pengetahuan dan pengembangan ilmu. Peningakatan ilmu penyuluhan mampu menjelaskan secara ilmiah terntang perubahan perilaku manusia dengan menerapkan pendekatan pendidikan pada orang dewasa (androgogy), berkomunikasi dan melakukan sesuai dengan alur sosial, ekonomi, budaya dari masyarakat dan lingkungan.

\section{KESIMPULAN DAN SARAN}

\section{Kesimpulan}

Kesimpulan dari studi ini adalah hubungan penyuluhan peternak Kelompok Ternak Sapi Potong Rojo Koyo Desa Senggreng Kecamatan Sumberpucung Kabupaten Malang pada proses adopsi inovasi pembuatan konsentrat mandiri adalah cenderung positif: pemilihan bahan baku dengan perubahan perilaku keterampilan (psychomotor). Hubungan yang cenderung positif dan negatif terdapat pada notulensi terhadap perubahan perilaku sikap (Affective).

\section{Saran}

Peran penyuluhan seperti diseminasi dan supervisi disarankan untuk lebih dimanfaatkan terutama dalam proses penjualan konsentrat mandiri. 


\section{DAFTAR PUSTAKA}

Astiti, N. M. A. G. (2018). Sapi Bali dan Pemasarannya. Denpasar:

Warmadewa University Press.

Bandyopadhyay, M., Chakraborty, R., \& Raychaudhuri, U. (2007). A process for preparing a natural antioxidant enriched dairy products (sandesh). LWT-Food Sci. Technology, 40, 842-851.

Bindari, Y. R., Shrestha, S., Shrestha, N., \& Gaire, T. N. (2010). Effects of nutrition on reproduction- A review. Advances in Applied Science Research, 4(1), 421-429.

Funston, R. (2006). Nutrition and Reproduction Interactions. Proceedings Applied Reproductive Strategies in Beef Cattle October 3 and 4. Rapid City: South Dakota.

Kurnia sari, D. D. (2016). Pengaruh pakan tambahan berupa ampas tahu dan limbah bioetanol berbahan singkong (manihot utilissima) terhadap penampilan sapi bali (bos sondaicus). Buletin Peternakan, 40(2), 107-112. https://doi.org/10.21059/buletinpetern ak.v40i2.9191

Nanda, D. D., Purnomoadi, A., \& Nuswantara, L. (2014). Penampilan produksi sapi bali yang diberi pakan dengan berbagai level pelepah sawit. Agromedia, 32(2), 54-63.
Sampurna, I., \& Suatha, I. (2010). Pertumbuhan alometri dimensi panjang dan lingkar tubuh sapi bali jantan. Jurnal Veteriner, 11(1), 46-51.

Siswanto, M., Patmawati, N. W., Trinayani, N. N., Wandia, I. N., \& Puja, I. K. (2013). Penampilan reproduksi sapi bali pada peternakan intensif di instalasi pembibitan pulukan. Veterinary Science and Medicine Journal, 1(1), 11-15.

Tahuk, P., \& Dethan, A. (2010). Performance of Bali bull in greenlot fattening by farmers when rainy season in Timor Island. Journal of the Indonesian Tropical Animal Agriculture, 35(4), 257-261. https://doi.org/10.14710/jitaa.35.4.257-261

Tonbesi, T. T., Ngadiyono, N., \& (Sumadi), S. (2012). The potency estimation and performance of Bali cattle in Timor Tengah Utara Regency, East Nusa Tenggara Province. Buletin Peternakan, 33(1), 30-39. https://doi.org/10.21059/buletinpetern ak.v33i1.132

Wiyatna, M. F. (2007). Perbandingan indek perdagingan sapi-sapi Indonesia (Sapi Bali, Madura,PO) dengan Sapi Australian Commercial Cross (ACC). Jurnal Ilmu Ternak Universitas Padjadjaran, 7(1), 22-25. https://doi.org/10.24198/JIT.V7I1.2227 